\title{
Qualitative Environmental Health Research: An Analysis of the Literature, 1991-2008
}

\author{
Pesquisa qualitativa de saúde ambiental: \\ Uma análise da literatura, 1991-2008
}

M adeleine Kangsen Scammell ${ }^{1}$

${ }^{1}$ Department of

Environmental $\mathrm{H}$ ealth, Boston University School of Public $\mathrm{H}$ ealth, Boston,

M assachusetts. 715 Albany

St., T4W. Boston MA

02118 USA.mls@bu.edu
Abstract Qualitative research uses nonnumeric data to understand people's opinions, motives, understanding, and beli efs about events or phenomena. In this analysis, I report the use of qualitative methods and data in the study of the relationship between environmental exposures and human health. A primary search for peer-reviewed journal articles dated from 1991 through 2008 included the following three terms: qualitative, environ*, and health. Searches resulted in 3,155 records. Data were extracted and findings of articles analyzed to determine where and by whom qualitative environmental health research is conducted and published, the types of methods and analyses used in qualitative studies of environmental health, and the types of information qualitative data contribute to environmental health. The results highlight a diversity of disciplines and techniques among researcherswho used qualitative methods to study environmental health. N early all of the studiesidentified increased scientific understanding of lay perceptions of environmental health exposures. This analysis demonstrates the potential of qualitative data to improve understanding of complex exposure pathways, including the influence of social factors on environmental health, and health outcomes.

key words Anthropology, Environmental epidemiology, Qualitative methods, Sociology, Theory
Resumo Pesquisa qualitativa usa dados não numéricos para entender opiniões, motivos e crenças sobre eventos efenômenos. N esta análise, o uso de métodos e de dados qual itativos é reportado no estudo da relação entre exposição ambiental esaúde humana. U ma pesquisa preliminar por artigos de 1991 a 2008 incluiu os três seguintes termos: qualitativo, ambientee saúde. A pesquisa resultou em 3.155 registros. Dados foram extraídos e artigos analisados para determinar ondee por quem a pesquisa de saúde ambiental foi conduzida e publicada, os tipos de métodos e análises usados em estudos qualitativos de saúde ambiental e os tipos de dados de informação qualitativa que contribuem para a saúde ambiental. Os resultados ressaltam uma diversidade de di sci plinas e técnicas entre pesquisadores que usaram métodos qualitativos para estudar saúde ambiental. Q uase todos os estudos i dentificaram um aumento da compreensão científica de percepções de exposi ções de saúde ambiental. A análise demonstra o potencial de dados qualitativos para melhorar a compreensão de caminhos de exposição complexos, incluindo a influência de fatores sociais em saúde ambiental e resultados.

Palavras-chave Antropologia, Epidemiologia ambiental, M étodos qualitativos, Sociologia, Teoria 
Qualitative methods are commonly used in the social sciences and in a variety of disciplines re lated to public health. Several articles published as editorials or commentaries in public and environmental health journals in recent years have advocated for the use of more qualitative methods in environmental health research (Brown 2003; Foster and Sharp 2005; Lobdell et al. 2005; Rice et al. 2003).

Qualitative research frequently refers to a variety of approaches and techniques that may vary depending on the discipline(Snapeand Spencer 2003). What they share is the recognition that when studying the social world, methodology must allow for the analysis of the construction of socially and culturally derived meaning and of human interpretation of reality. Qual itativestudies are generally designed to explore perceptions of reality or, more specifically, perceptions of a phenomenon.

There are a number of widely agreed upon characteristics of qualitative research. Sources of qualitative data can be grouped into three categories: interviews (one-on-one and group), observations, and documents (Patton 2002). Qualitative interviews are often designed to ask openended questions, enabling the researcher to hear and make sense of responses from the people who are being interviewed without predetermining their points of view by fixing response categories ahead of time, as in quantitative survey methodology. Conventional survey methods do not allow for additional, surprising, or multifaceted responses. Questions likely to elicit a "yes" or "no" response are not open-ended, nor are questions that lead people to a type of response, for example, not stressful, somewhat stressful, very stresfful. Another characteristic of qualitative research is the explicit consideration of the researchers' perspective. Q ualitative researchers are usually a primary data collection instrument (i.e., as opposed to a written survey instrument or an air monitor). Explicit recognition of theoretical perspectives helps researchers check and control potential biases in data interpretation. Reflexivity and bracketing are both forms of selfreflection practiced by qualitative researchers and involve evaluation of their roles in unintentionally tainting or manipulating data (Finlay 2002; Patton 2002).

One important aim of qualitative analysis is to make sense of the data while allowing the voice of the participants to be heard. A common way to do this is by using quotes and narrative descriptions in the output of qualitative research.
Finally, analysis of qualitative data requires some degree of abstraction or generalization as patterns are identified in the data and related to larger constructs or theories. A definition of theory frequently cited by qualitative scholars is "a set of interrelated constructs, definitions, and propositions that present a rational view of phenomena by explaining or predicting relationships among those elements" (Ulin et al. 2005). The theoretical contributions of qualitative research come from the interpretation and analysis of qualitative data.

As for the theoretical relationship between qualitative data and environmental health, two overarching paradigms-interpretivism and positivism - characterize how people view the world and, some would argue, imply how the world should bestudied (Ulin et al. 2005). (Within each are various nuanced theoretical traditions.) Positivist methods are based on the belief that the world consists of observable facts that exist, or are true, independent of human cognition (Wing 2003). U sually such observations are quantitative measurements (i.e., enumeration of the "independent variables" and their relation ship with the "dependent variables") (Wing 1994). On the other hand, interpretivism is concerned with themeaning of reality, not with measuring reality per se. Some interpretivist scholars would assert that no single reality exists and that all reality is filtered through theperception of human cognition (U lin et al. 2005). According to this logic, because all observations are acts of unconscious interpretation, interpretivist research focuses on meanings and is usually represented by qualitative assessments (Ulin et al. 2005). In February 2005, a commentary (Foster and Sharp 2005) published in Environmental $\mathrm{H}$ ealth Perspectives (EH P) suggested the use of qualitative data as a means for generating hypotheses as well as for facilitating the multilevel analysis of Qualitative methods are commonly used in the social sciences and in a variety of disciplines related to public health. Several articles published as editorials or commentaries in public and environmental health journals in recent years have advocated for the use of morequalitativemethodsin environmental health research (Brown 2003; Foster and Sharp 2005; Lobdell et al. 2005; Riceet al. 2003).

Qualitative research frequently refers to a variety of approaches and techniques that may vary depending on the discipline(Snapeand Spencer 2003). What they shareis therecognition that when studying the social world, methodology must allow for the analysis of the construction 
of socially and culturally derived meaning and of human interpretation of reality. Q ualitativestudies are generally designed to explore perceptions of reality or, more specifically, perceptions of a phenomenon.

There are a number of widely agreed upon characteristics of qualitative research. Sources of qualitative data can begrouped into three categories: interviews (one-on-one and group), observations, and documents (Patton 2002). Qualitative interviews are often designed to ask openended questions, enabling the researcher to hear and makesense of responses from the people who are being interviewed without predetermining their points of view by fixing response categories ahead of time, as in quantitative survey methodology. Conventional survey methods do not allow for additional, surprising, or multifaceted re sponses. Questions likely to elicit a "yes" or "no" response are not open-ended, nor are questions that lead people to a type of response, for example, not stressful, somewhat stressful, very stressful. Another characteristic of qualitative research is theexplicit consideration of theresearchers' perspective. Qualitative researchers are usually a primary data collection instrument (i.e., as opposed to a written survey instrument or an air monitor). Explicit recognition of theoretical perspectives helps researchers check and control potential biases in data interpretation. Reflexivity and bracketing are both forms of self-reflection practiced by qualitativeresearchers and involve evaluation of their roles in unintentionally tainting or manipulating data (Finlay 2002; Patton 2002).

One important aim of qualitative analysis is to makesense of the data while allowing the voice of the participants to beheard. A common way to do this is by using quotes and narrative descriptions in the output of qualitative research. Finally, analysis of qualitative data requires some degree of abstraction or generalization as patterns are identified in the data and related to larger constructsor theories. A definition of theory frequently cited by qualitative scholars is "a set of interrelated constructs, definitions, and propositionsthat present a rational view of phenomena by explaining or predicting relationships among those elements" (Ulin et al. 2005). The theoretical contributions of qualitative research come from theinterpretation and analysis of qualitative data.

As for the theoretical relationship between qualitative data and environmental health, two overarching paradigms-interpretivism and positivism-characterize how people view the world and, some would argue, imply how the world should bestudied (Ulin et al. 2005). (Within each are various nuanced theoretical traditions.) Positivist methods are based on the belief that the world consists of observable facts that exist, or are true, independent of human cognition (Wing 2003). Usually such observations are quantitativemeasurements (i.e., enumeration of the "independent variables" and their relationship with the "dependent variables") (Wing 1994). On the other hand, interpretivism is concerned with the meaning of reality, not with measuring reality per se. Some interpretivist scholars would assert that no single reality exists and that all reality is filtered through the perception of human cognition (Ulin et al. 2005). According to this logic, because all observations are acts of unconscious interpretation, interpretivist research focuses on meanings and is usually represented by qualitativeassessments (Ulin et al. 2005). In February 2005, a commentary (Foster and Sharp 2005) published in Environmental Health Perspectives (EHP) suggested the use of qualitative data as a mean sfor generating hypotheses as well as for facilitating the multilevel analysis of individual, contextual, and structural factors that contribute to complex diseases. The authors, an anthropologist and a philosopher, recommended that researchers consider a hybrid study design that includes qualitative and quantitative methods. For example, when studying disease susceptibility, Foster and Sharp (2005) suggested that qual itative data will "empirically specify quantitatively testable practices rather than proxy identities or categories such as culture, ethnicity, gender, and class." They concluded that "qualitative methods such as ethnography may become an interdisciplinary companion to epidemiology." Rice et al. (2003) also suggested that qualitative data may help explain variation in quantitative exposure methods.

Three months after the Foster and Sharp article appeared, a feature article of the Journal of Environmental $\mathrm{H}$ ealth (Lobdell et al. 2005), whose first author is an epidemiologist at theU.S. Environmental Protection Agency, argued that qualitative research methods are underused by environmental health researchers. Lobdell et al. (2005) suggested a variety of ways that focus groups are and may be used to study environmental health, described specific techniques for conducting focus groups, and provided how-to references for interested readers.

The appreciation for qualitative methods by epidemiologists is not new. According to Dunn and Janes (1986), qualitative anthropological 
knowledgehas been considered "useful" by epide miologists since the 1950s with many collaborative studies conducted through the 1970s. Interdisciplinary research involving anthropologists and epidemiologists was most common in studies conducted in non-Western societies and among migrant groups in the United States and Europe. The focus of these studies was usually behavior and its role in disease etiology, which led to the development of strategies for modifying behavior (Trostle 1986b). Trostle (1986a) observed that when qualitative data are included in epidemiological studies, anthropologists would often "find themselves working primarily as epidemiologists," as opposed to what is more recently referred to as transdisciplinary research where methods transcend the techniques of any single discipline (Rosenfield 1992; Stokols 2006). Trostle (1986a) cited few instances where anthropologists and epidemiologistsworked as coarchitects in thecre ation of hybrid or new study designs.

Recent articles on the value of qual itative data in the study of environmental health argue that qualitative methods are especially important to community-based environmental health research because of their ability to engage residents regarding local environmental health problems. Qualitative methods "provide a way to produce community narratives that give voice to individuals and characterizethe community in afull and complex fashion" (Brown 2003).

Such editorials and commentaries are compelling, but with few exceptions they do not include evidence of environmental epidemiologists using qualitative data or working with qualitative social scientists to study the relationship between environmental exposures and health outcomes. This article presents the results of an analysis of qualitative methods and data used in the study of environmental health and published in peer-reviewed scientific journals. Thestudiesincluded in this analysis are ones that used nonnumerical, qualitativedata on the relationship between environmental exposures and human health.

The objectives of this study were to identify where and by whom qualitative environmental health research is conducted and published, examine the types of methods and analyses used in qualitative studies of environmental health, and determine what types of information qualitative data contribute to the study of environmental health.

\section{Data Sources}

Here, I review environmental health research that was published as a journal article, used qualitative methods, and was published in English. Books and monographs are not included. In the natural sciences, published articles are "the coin of the realm," for promotion and recognition, rather than thebook-length format morecommon in the humanities and social sciences. Each form of discourse has a value specific to its context. This analysis is limited to the type of discourse represented in peer-reviewed journal articles.

\section{Inclusion criteria}

All studiesincluded in this analysis report findings from qualitative research. Mixed-method studies that use both qualitativeand quantitative techniques to collect and analyze data are also included. Although environmental health has typically concerned itself with the physical human health outcomes of exposure to environmental hazards, this analysis expands the definition of health effect to include mental and psychosocial health outcomes. Several articles are included that examined exercise or physical activity as an outcome.

Exposures considered in this analysisinclude physical, chemical, and biological exposures in people's immediate or proximate surroundings (e.g., soil, air, water, food, and homes) and that affect peoplein their neighborhoods, communities, or workplaces. Articles that focus on social determinants of health as an exposure are included in this analysis only when examined in relation to a specific chemical, physical, or biological environmental exposure.

\section{Exclusion criteria}

A large number of qualitative articles with a focus on the transmission of biological and infectious agents primarily via social and behavioral activities (e.g., sexually transmitted infections) are excluded. However, studies that included biological agents such as malaria and cryptosporidium are included by virtue of their exposure being directly associated with environmental conditions (i.e., vector breeding habitat and contaminated water). Program or project evaluations, reviews, and qualitative meta-syntheses of data from multiplestudies are excluded.

Three areas of research that pertain to the field of environmental health but are not included in this analysis are briefly recognized. First, because this review focuses on proximate mi- 
crolevel environmental hazards, studies that examine distal or macrolevel environmental concerns are excluded (i.e., in the domain of global change and environmental sustainability). Second, although public understanding of science is afield of research that provides data on how people translate or understand scientific information, and is important to environmental health scientists and risk communicators, it isnot astudy of environmental health per se, so such studies were excluded from the review. Third, studies of risk perception that examined the cognitive process of risk judgments that people make when they are asked to characterize and evaluate hazardousactivities and technologies were excluded.

Search strategy

A primary search included three terms: qualitative, environ*, and health [the asterisk (*) tells the search engine to include anything after that segment (e.g., environment, environs, environmental) ]. The time frame of the search was from 1991 through 2008, beginning 2 years before the $\mathrm{N}$ ational Institute of Environmental Health Sciences (NIEHS) Environmental Justice Partnerships for Communications funding program, which encouraged multidisciplinary relationships among environmental health researchers. The primary search was conducted on ISI Web of Knowledge/Web of Science (Thomson Reuters, New York, NY), which includes social sciencecitation indices and the $\mathrm{N}$ ational Library of Medicine's M ED LINE database. M ore targeted searches included key-word and full-text searches in the electronic archives of the journal EHP and in the "Qualitative Research" collection of the American Journal of Public H ealth (AJPH), which dates back to 2000. These searches resulted in 3,155 records combined. N early 2,000 articles wereimmediately excluded because they werenot qual itative papers and merely included the word "qualitative" in the text, or because they clearly met other exclusion criteria. The abstracts of approximately 1,160 articleswere used to screen for papers that employed qualitative methods and met the definition of environmental health. If there was uncertainty, the paper was obtained and examined. The full texts of all papers included in this analysis were obtained, and the referencelists of these papers were examined for additional articles.

\section{Data extraction}

The structure of this analysis borrows from literature on writing reviews (Badger et al. 2000; Higginsand Green 2006), quantitativemeta-anal- yses (Petitti 2000), and qualitative meta-syntheses (Noyes and Popay 2007; Sandelowski et al. 1997). However, this is not a traditional review, meta-analysis, or meta-synthesis because not all the studies are on the same exposure or outcome (e.g., outcomes of the same clinical trial, or analyses of the same event or phenomenon), nor are the findings pooled and compared with a common metric.

As each article was identified for inclusion, it was read (or reread) and (re)considered for its ability to meet inclusion criteria. For every study, the following questions were asked: I s this a study about a physical, biological, or chemical exposure? Does this study discuss exposure in relation to health or perceived health risk? D oes this study discuss health, or perceived health, in relation to exposure?

Once articles were included in the analysis, information relevant to the questions driv-ing the analysis was extracted, entered into an Excel spread sheet, and further analyzed. Columns included journal title, authors, year of publication, environmental health topic (i.e., exposure and/ or health outcome), qualitative methods, quantitative methods, analyses (of qualitative and quantitativedata), findings and conclusions, author associations and disciplines, key words, context of study (if part of larger study or project), funding source, and country. Following the convention of meta-syntheses of qualitative studies, no studies are excluded for reasons of quality, nor is the quality of studies evaluated in this analysis (Sandelowski et al. 1997). Descriptions of qualitative research methods were extracted from each article, along with mentions of theoretical and analytical frameworks. Data for the findings and conclusion sections of all studies were initially extracted from the article abstracts so that the approach to data extraction would be as uniform as possible. When no abstracts were available, or when abstracts did not provide such information, the actual findings and conclusion sections of each article were examined for such data. Content of the spreadsheet was quantitatively summarized (e.g., number of articles published per year, number of articles written by each author, number of theories identified). These data were also examined for the frequency of specific exposures and outcomes. Qualitative content analysis was conducted to address each of the stated objectives. Content analysis refers to "any qual itative data reduction and sense making effort that takes a volume of qualitative material and attempts to identify core consistencies and 
meanings" (Patton 2002). Specifically, the findings of articles were analyzed for themes, or frequently repeated ideas, in the types of information reported.

To aid thequal itative content analysis, the three columns of theExcel spreadsheet with largequantities of text (qualitative methods, analyses, and findings and conclusions) wereimported as three separate documents into the qualitative analysis software NVIVO [version 7; QSR International (Americas), Cambridge, MA]. These data were then coded by the author. Codes are words and phrases used to tag units of data. Coding data, in this case article text, enables analysts to retrieve codes and associated data and to assign values of frequency, presence/absence, and relationship with other codes (M acQueen et al. 1998). Eventually these may be grouped under a theme that has been identified by the analyst(s). NVIVO preserved thetable format of Excel so that coded data would not be disassociated with the authors of the study and year of publication (i.e., data retrieved by codes included the coded text and theidentifying information). All data werecoded with a total of 28 codes in the final code book I developed. Analysis was conducted twice at two distinct periods of timeto achieve high intrarater reliability (Stemler 2001). Themes wereidentified in the data using the coverage and reference data provided by NVIVO, as well as consideration of a code's meaning and its relationship with other codes. [ See Supplemental M aterial, Table 1 (doi:10.1289/ehp.0901762) for a sample code book, and Supplemental Material, Figure $1 \mathrm{de}$ picting the steps of qual itative analysis.]

\section{Data Synthesis}

Thefollowing results were obtained from this analysis and grouped by the research objectives.

\section{Publishing qualitative environmental health research}

Ninety-one articles met all inclusion criteria and were derived from 87 studies. The vast majority of articles (70 of 91) included multipleauthors from three or more institutions or areas of discipline within a university. More than half of the articles included one or more authors from university departments within public health (e.g., environmental health, epidemiology, family and community medicine, health behavior and education, and health policy and management). Other health-related fields represented included clin-
Table 1. Journals with environmental health studies using qualitative methods (1991-2008).

\begin{tabular}{|c|c|}
\hline Journal & $\mathrm{N} N$ articles \\
\hline Acta Trop & 1 \\
\hline Afr Health Sci & 1 \\
\hline Afr J AIDS Res & 1 \\
\hline AAOHN J & 1 \\
\hline Am J Health Behav & 1 \\
\hline Am j H ealth Promot & 2 \\
\hline Am j Ind Med & 3 \\
\hline Am J Public Health & 3 \\
\hline BMC Public Health & 2 \\
\hline Braz J Poult Sci & 1 \\
\hline Chronic Dis Can & 1 \\
\hline Crit Soc Pol & 1 \\
\hline Ecohealth & 2 \\
\hline Ecol Society & 1 \\
\hline EcoSystem Health & 1 \\
\hline Environ $\mathrm{H}$ ealth Perspect & 7 \\
\hline Energy Policy & 1 \\
\hline Environ Behav & 1 \\
\hline Environ Urban & 1 \\
\hline Global Environ Change & 1 \\
\hline H ealth & 1 \\
\hline Health Place & 8 \\
\hline Health Risk Soc & 1 \\
\hline Human Ecol Risk Assess & 1 \\
\hline Hum Organ & $\overline{1}$ \\
\hline Indoor Air & 1 \\
\hline Inj Prev & 1 \\
\hline Int J H ealth Serv & $\begin{array}{l}1 \\
1\end{array}$ \\
\hline Int J Hyg Environ Health & 1 \\
\hline Int J Occup Environ $\mathrm{H}$ ealth & 2 \\
\hline Int J Urban Reg Res & 1 \\
\hline J Adolesc Res & 1 \\
\hline J Agric Saf Health & 1 \\
\hline Jiosoc Sci & 1 \\
\hline J Epidemiol Community Health & 2 \\
\hline J Health Care Poor Underserved & 1 \\
\hline N nutr Educ Behav & 1 \\
\hline J Public Health & 1 \\
\hline U Urban Health & 2 \\
\hline Malar J & 1 \\
\hline M ed Anthropol & 1 \\
\hline $\mathrm{N}$ oise $\mathrm{H}$ ealth & 1 \\
\hline Nurs H ealth Sci & 1 \\
\hline O ccup M ed & 1 \\
\hline Pediatr Pulmonol & 1 \\
\hline Popul Stud (Camb) & 1 \\
\hline Prof Geogr & 1 \\
\hline Psychol Health & 1 \\
\hline Public Health Nurs & 2 \\
\hline Qual Health Res & 1 \\
\hline Risk Anal & 1 \\
\hline Sci Total Environ & 1 \\
\hline Sociol Health IIIn & 1 \\
\hline Sociol Inq & 2 \\
\hline Soc Sci Med & 8 \\
\hline Sci Technol Human Values & 1 \\
\hline Waste $M$ anage Res & 1 \\
\hline West J Nurs Res & 1 \\
\hline World Dev & 1 \\
\hline Total & 91 \\
\hline
\end{tabular}




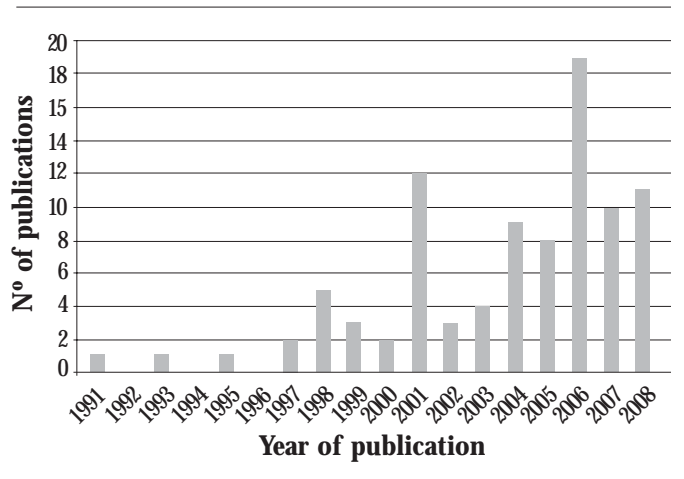

Figura 1. Number of articles published per year (1991-2008).

ical epidemiology, dermatology, health sciences, nursing, oncology, psychiatry, psychology, and tropical medicine. Areas of discipline outside of traditionally identified health fields included anthropology, geography, oceanography, urban and regional studies, and sociology. Eight included authors from government agencies and community-based organizations that participated in the research. Authors werefrom, and studies were conducted in Australia, Bangladesh, Belgium, Botswana, Brazil, Canada, Croatia, Cuba, Denmark, Finland, Germany, Ghana, Italy, Japan, Kenya, Nepal, the Netherlands, New Zealand, Nicaragua, Nigeria, Pakistan, Philippines, South Africa, Sweden, Syria, United States, and the United Kingdom and among native Australians and Alaskans. The most articles were written by authors in theU nited States, followed by the United Kingdom and then Canada.

Articles were published in 59 different journals (Table 1), with the most publications in a single journal totaling eight. Both journals with eight articles, Social Science and M edicine and $\mathrm{H}$ ealth and Place, are self-described interdisciplinary journals. This comparison among number of publication by journals does not takeinto consideration the frequency of publication for each journal or the relative size of each issue (number of articles published).

Three of the seven articles published by EHP arein mini-monographs (Furgal and Seguin 2006; Green et al. 2002; Lipscomb et al. 2005) and do not conform to the traditional format for a research publication in EH P (i.e., including a structured abstract and the traditional research article format of introduction, methods, results, and discussion). Three other EH P articles were published in the same supplement, titled " $M$ igrant and Seasonal Farmworkers and Pesticides: CommunityBased Approaches to Measuring Risks and Reducing Exposure" (Arcury and Quandt 2001). These articles also did not necessarily follow the research article format (Flocks et al. 2001; M cCauley et al. 2001; Thompson et al. 2001). The seventh article in EHP (Thompson et al. 2008) was published as a traditional research articleand reports further results of an intervention described in the aforementioned supplement. Similarly breaking from the usual journal format, two of thethreearticlesin AJPH werepublished in the column "Public Health Matters" or "Framing H ealth M atters" (H éon-Klin et al. 2001; Wing et al. 2008) and not in the "Research and Practice" section of thejournal, where papers reporting the results of research are typically published.

There appears to be an overall trend in the number of articles published per year (Figure 1), with noticeable spikesin 2001 and 2006. The one eligible article published in 1991 was funded by the O ntario M inistry of Environment with sponsorship by the Canadian M ental $\mathrm{H}$ ealth Association and was part of an ongoing "interdisciplinary research program to determine the impacts of exposure to environmental contaminants on human health and welfare and to develop strategies to reduce their adverse effects" (Taylor et al. 1991). Two of thethree articles published in 1999 appear to be products of the same program funded in 1991, with the same funding source identified in the acknowledgments (Elliott et al. 1999; James and Eyles 1999).

Methods and analysis reported in studies

This analysis identified a variety of qualitative techniques reported, with most studies relying on one-on-one interviews for their qualitative data. A subset of the studies also relied on quantitative techniques (i.e., mixed-methods qualitative and quantitativeresearch). A pproaches to data analysis were diverse, with details absent from a large number of studies.

\section{Interviews}

M ost studies (65) used one-on-oneinterviews to collect data, with as few as six individuals interviewed in a study (Larsson et al. 2006) and as many as 93 (M essias and Lacy 2007). Approximately half of these studies also included data derived from other qualitativedata collection techniques, such as focus groups (i.e., a group interview) and observation. Thirty-two articles reported focus groups, with numbers of groups 
per study ranging from one (Bush et al. 2001) to 32 (Amin and Basu 2004).

\section{Observation}

Sixteen studies included observation techniques. For example, a study of children's vulnerability to water-related disease hazard in northern Pakistan conducted by a researcher from an American institution included observations with 30 households on details of household structure, household decision making, divisions of labor, child care, and recent illness events (Halvorson 2003).

\section{Text analysis}

Ten studies used document analysis as a data collection technique. Examples of sourcesincluded newspaper reports (H arper 2004), transcripts of congressional hearings on Gulf War illness (Shriver 2001), local print media and newsletters (Vandermoere 2006), e mails (Imai et al. 2008), and the scientific literature in medical, public health, and epidemiologic journals (Brown et al. 2004; Wernham 2007).

\section{Participatory research}

Eleven articles described theuse of participatory research methods, such that the authors' research was designed or conducted in collaboration with the population being studied (Israel et al. 2006; Lambert et al. 2006; Wing et al. 2008). Three articles described their qualitative work as a component of community-based participatory research (Flocks et al. 2001; Lipscomb et al. 2005; McCauley et al. 2001). Neudoerffer et al. (2005) trained and hired members of the local community to be focus group facilitators and described participatory research as one method among many that are central in a vision of science for social change: "M ethodological pluralism must be central to any new science for sustainability." In their article, epidemiologic methods were complemented with qualitative tools described as participatory action research, Freirian conscientization, and appreciative inquiry. Several such approaches were described without elaboration, challenging the ability of a reader who is not familiar with this terminology to fully understand or appreciate the methods. Participatory rural appraisal was used to study climate change and vulnerability among Canadian northern Aboriginal communities (Furgal and Seguin 2006). Action research ethnography was conducted in an urban shantytown of Lagos, Nigeria, and was described as a qualitative strategy, "based on di- alogical inquiries" (Jarvela and Rinne-Koistinen 2005). The better known techniques such as focus groups, in-depth interviews, and observation were also included in these studies.

M ixed qual itativeand quantitativemethods

Of the 91 articles, 35 included quantitativeand qualitative data. More than half (18) of these mixed-methods studies were primarily epidemiologic studies that included a qual itative component. In four studies the only source of qualitative data came from openended (qualitative) questions on primarily closed-ended (quantitative) questionnaires (D oria et al. 2006; Elliott et al. 1999; Moffatt et al. 1995; Warr et al. 2007). M ore often, qual itative data from questionnaires was supplemented with data from observations and in-depth interviews. In several cases interviews followed up, or provided clarification on, survey data. On the other hand, preliminary interviews in at least two studies helped to construct and validate a larger, subsequent quantitativesurvey (D ay 2006; Engvall et al. 2004). One study included in-depth interviews with 37 workers and used that information to construct a job exposure matrix (Lipscomb et al. 2005).

Theoretical frameworks and analyses

Despitedifferences in opinion about theextent to which specific theories should inform qualitative analysis, the contribution to theory was considered a defining characteristic of qualitative research. Theoretical frameworks have been called "the analyst's reading glasses" and are conceptual models used in the process of interpretation (M alterud 2001). Roughly half (18) the environmental health research articles in this analysismade no reference to theoretical frameworks. Twentythreearticles included no description of how qualitative data wereanalyzed. Three of thesewerepublished in the journal EH P (Flocks et al. 2001; Lipscomb et al. 2005; M cCauley et al. 2001), and none were traditionally structured research articles.

More than 30 articles described coding as a key component of analysis, with grounded theory being the most commonly cited analytic framework (Aragón et al. 2001; Bush et al. 2001; Green and $\mathrm{H}$ art 1998; H ammal et al. 2005; Larsson et al. 2006; Schaefer-M cDaniel 2007; Timmermans 2007; Trayers et al. 2006). Proponents of grounded theory research have suggested that analysts approach the data with no substantivetheories in mind. All theories that emerge from the analyses are to be grounded entirely in the data, without preconceived notions of theories to which thefind- 
ings may contribute. Grounded theory, which is strongly dependent on the process of coding, was developed by qualitativeresearchers who attempted to formalize their empirical methods when quantitative research was dominant in behavioral and social sciences (Snape and Spencer 2003).

Second to grounded theory was themen-tion of neighborhood effects. Although not referred to as an analytic framework per se, the theory of neighborhoods affecting health was explored in seven articles (Bowieet al. 2005; Israel et al. 2006; Michael et al. 2006; Schaefer-M CD aniel 2007; Songsore and M CGranahan 1998; Timmermans 2007; Warr et al. 2007). Other theoretical perspectives referred to in the analyses include ecological theory (Salazar et al. 2004; Schaefer-M CD aniel 2007) and social constructionism (M offatt and PlessMulloli 2003; Shriver 2001; Shriver et al. 1998). Two articles referred to the environmental stress and coping literature as an analytic framework (H aines et al. 2003; Wakefield et al. 2001).

\section{Qualitative contribution}

to environmental health sciences

In this analysis, all studies were analyzed from the perspective of an environmental epidemiologist, meaning that each study was examined for its contribution to environmental heal th understanding with respect to associations between a given environmental exposure and health outcome. Some studies naturally provided more information on one or the other, rather than measure a perceived or actual association between the two. $\mathrm{H}$ alf a dozen studies were designed specifically to examine what might beconsidered effect measure modifiers (Amin and Basu 2004; Bickerstaff and Walker 2001; Day 2006) (e.g., socioeconomic status and sex). In what follows, the analysis of the studies' findings and conclusions with respect to the types of information they contributed to the field of environmental health were organized under four headings: exposures, health outcomes, planning an intervention, and factors that influenceenvironmental health. Thesewerenot mutually exclusive categories, and a single article may have been mentioned under all headings.

\section{Exposures}

Nearly all 91 studies provided data on environmental exposures. More than one-third of the studies focused on exposures known by scientists to beassociated with heal th outcomes (e.g., lead in soil, the consumption of contaminated food or water, inhalation or dermal contact with pesticides, and air pollution) (Figure 2).

M ost often, qualitative data identifies beliefs, activities, or behaviors that would increase exposure. For example, includ-ing children in focus groups about exposure to pesticides enabled the identification of a "largenumber of activities that may poten-tially expose children to pesticides through both direct and indirect routes" (CoOper et al. 2001). A dozen studies examined the perceived and actual exposures to residents living near pollution sources, including heavily industrial areas (Bush et al. 2001), solid waste facilities (Elliot 1998; Eyles et al. 1993; Taylor et al. 1991), confined area feed operations (Tu et al. 1997; Wing et al. 2008), mining operations (M offatt and Pless-Mulloli 2003), and sites of a contamination event or disaster (Barnes et al. 2002; M essias and Lacy 2007; Shriver et al. 1998). Lambert et al. (2006) conducted a mixed-methods study using qualitative inter-views, quantitative survey data, environmental sampling, and contaminant dispersion mod-els to identify exposures in residential areas near the tar ponds of a cokeand steel factory. Respondents in all areas of the study described the effects of ash deposition in the form of "dust," "coal dust," "dirt," and "fall out" on and in their homes, cars, and laundry and in their community. According to Lambert et al. (2006), there were no differences in odors reported between the communities considered by authorities as adversely affected versus those considered to befreefrom contamination. Residents in areas supposedly free from con-tamination were reported to have provided researchers additional knowledge of child-specific exposures.

A relatively large number of studies examined aspects of the built environment or neigh-

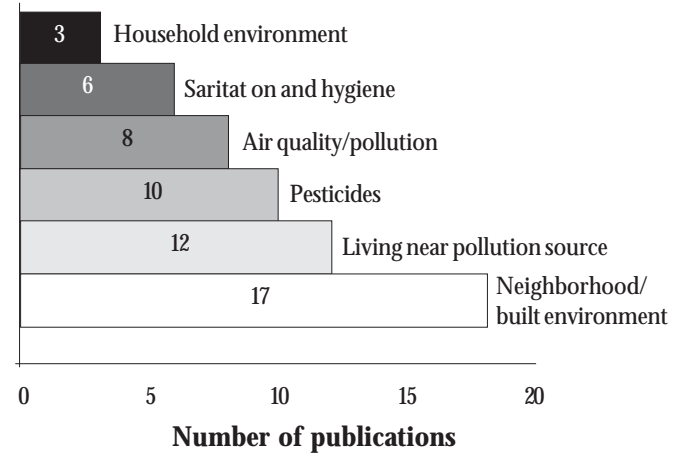

Figura 2. Environmental exposures studied in three or more publications. 
borhoods and possible associations with physical activity (Kamphuis et al. 2007; Krenichyn 2006; M ichael et al. 2006; Regan et al. 2006; Richards and Smith 2007; Ries et al. 2008; Trayers et al. 2006; Yen et al. 2007). M ost of these articles, and nine addi-tional articles with a focus on neighborhood effects on health generally, were published since 2000 (Bolam et al. 2006; Bowieet al. 2005; Butchart et al. 2000; D ay 2008; Israel et al. 2006; Popay et al. 2003; Schaefer-M CDaniel 2007; Timmermans 2007; Warr et al. 2007).

A handful of studies identified new envi-ronmental exposures relevant to human health, or perceived to be hazardous by participants, that had not previously been considered by the study authors. Two such studies examined exposures of residents in urban renewal areas. In one, residents expressed concerns about potential risks due to gutting and demoli-tion of buildings, in contrast to expressing positivereactions to the urban renewal that had been expected by urban planners (Bowie et al. 2005). A separate study reported that an element of a proposed redevelopment plan intended to improve health was perceived by residents to be a harbinger of crime: Focus groups revealed that residents were concerned that the proposed cycle/ walkway would increasethevulnerability of their homes and cars to vandalism (Trayers et al. 2006). A third study that involved focus groups of African-American and Hispanic women in New York City identified a long list of environmental concerns among study participants that had not been anticipated by researchers, including needles, AIDS, drugs, violence, child abuse, domestic abuse, verbal and physical abuse, diseases, mental illness, pollution, rodents, brokendown buildings, and roaches (Green et al. 2002).

\section{Health outcomes}

Approximately one third of thestudies examined health outcomes. In most of these studies the health outcomes studied were previously suspected or known to researchers as generally being associated with environmental hazards (e.g., respiratory problems and air pollution, intestinal worms and hygienic practices). In some studies, however, health effects reported by participants represented new or previous undocumented outcomes. Focus groups and community workshops with Aboriginal communities in northern Canada associated respiratory stress among elderly participants with an increase in summer temperature extremes (Furgal and Seguin 2006). Participants described significant impacts of warming on ice travel and on hunting and fishing safety, with potential implications on food security and nutritional health. Furgal and Seguin (2006) wrote that there were anecdotal reports of "an increase in the number of accidents and drownings associated with poor or uncharacteristic ice conditions during times of the year that are predictable and typically very safe."

In a study on the nonauditory health effects of aircraft noise exposureamong children, $\mathrm{H}$ aines et al. (2003) noted that their results corroborated existing literature that noise annoyance is associated with feelings of mild irritation, anger, and fear. The authors were surprised to find that noise at home generated by neighbors created the highest annoyance among children: "N eighbor noise has been neglected in previous research of non-auditory health effects of noise exposure on children." A quantitative survey may not have captured this unanticipated information.

Environmental health research traditionally has not investigated associations between exposures to environmental hazards and mental and psychological health outcomes. However, a re current feature revealed in the analysis was the identification of psychosocial health effects directly and indirectly associated with environmental pollution. Psychosocial and stress-related health problems were the most frequently studied health outcomes among all the studies included in this literature analysis (Barnes et al. 2002; Bush et al. 2001; Elliott et al. 1999; Eyles et al. 1993; Haines et al. 2003; Israel et al. 2006; M offatt et al. 1995; Vandermoere 2006) (Figure 3). M offatt et al. (1995) conducted a study of anxiety and stress among residents living near a

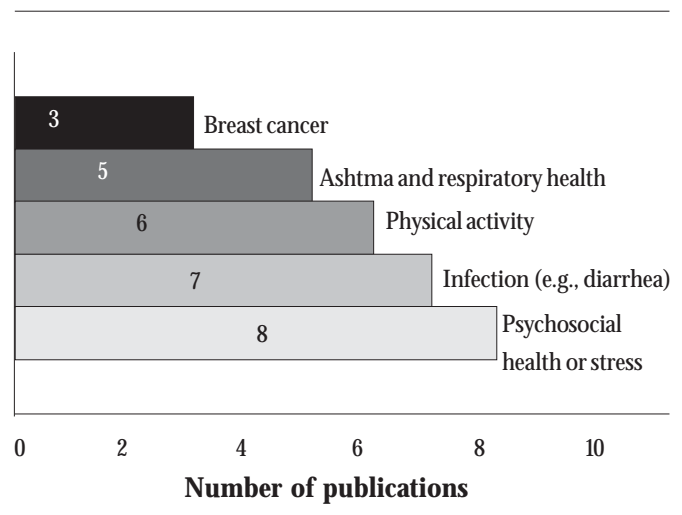

Figura 3. Health outcomes studied in three or more publications. 
coking works; they found that residents' suspicions that toxic emissions from the facility had damaged health were supported by the evidence of epidemiological studies on physical symptoms and health problems.

Planning an intervention

Several studies identified a target population for educational intervention based on the premise that people who are informed of health risks associated with exposure will act in ways to reduce or prevent exposure. A study on risk of waterrelated diseasein northern Pakistan identified men as important targets for health education, given their influence and power over resource allocation in the home, wherewater-related hazards are most effectively controlled (H alvorson 2004). In a study conducted in Brazil, Peres et al. (2006) identified women as a target for pesticide education, because they can "significantly and unknowingly increase their exposure to these chemical agents and put their homes and families at risk, especially when the family's regular clothes are washed together with contaminated ones."

Most intervention-oriented studies revealed a complex set of social conditions that influence beliefs and behaviors that contribute to exposure to environmental health hazards. This is particularly true of studies conducted in developing areas regarding perceptions of the biological and chemical exposures associated with sanitation and hygiene(Aragón et al. 2001; Espino et al. 1997; Halvorson 2003, 2004; $\mathrm{H}$ ammal et al. 2005; Neudoerffer et al. 2005; O Isen et al. 2001; Peres et al. 2006; Phaswana-M afuya and Shukla 2005) and with migrant farmworkers in the United States (Arcury et al. 2001, 2006; Flocks et al. 2001; M cCauley et al. 2001; Salazar et al. 2004).

Power relations were a theme of several studies where failure to acknowledge official and unofficial power structuresin the home, on thejob, or in a community may have resulted in incompleteor inadequateintervention. Power structures included gender relations and disruption in such relations brought about by economic and demographic changes (Halvorson 2003) and cultural, economic, institutional, and psychosocial factors. For example, qualitative interviews with agricultural growers and extension agents participating in a particular study revealed the belief that the danger of agricultural pesticides and the incidence of pesticide- related poisoning had been greatly exaggerated by the general public, the media, and the government (Rao et al. 2004). The authors notethat it was these people who were in positions of power to promote safe practices and enforce standards. These studies and their authors identified the importance of future interventions that consider the power structure that may exist in the relationship between those who are exposed and those who have the ability to mitigate such exposures.

Factors that influenceenvironmental health

The identification of a broader context of risk perception was prominent among the 91 studies. To borrow from one study, lay concepts of health and illness generally included theories that "describe how the characteristics of particular areas combine with wider macro-structural factors to damage health via complex pathways including material, lifestyle and stress-related factors" (Popay et al. 2003). Such material, lifestyle, and sociopolitical factors wereidentified in many of the studies.

A focus group study of women in New York City that identified a huge variety of environmental health concerns among partici pants concluded: "Few programs address, much less reduce, the powerful social, political, and economic forces that push urban residents into ill health" (Green et al. 2002). Thisillustrates the findings of many studies that context-specific social, cultural, and economic circumstances shape perceptions of environment and health, and the relationship between the two (i.e., environmental health). This finding has been corroborated by more than a dozen studies that compared perceptions and responses of participants by differences in socioeconomic status, for example, by conducting focus groups and interviews with residents from the same city or neighborhood but from demographically distinct areas within the city or neighborhood (Bickerstaff and Walker 2001; Bolam et al. 2006; Bush et al. 2001; Day 2006, 2008; I Israel et al. 2006; James and Eyles 1999; Kamphuis et al. 2007; Popay et al. 2003; Songsore and M CGranahan 1998; Stevens et al. 2004; Timmermans 2007; Wakefield et al. 2001; Yen et al. 2007). Additionally, day-to-day experience of environmental hazards, or health conditions, was reported to influence perception of environmental health. Several studies reported that participants rely heavily on personal, tangible, experience of pollution over scientific evidence regarding the extent of exposures and health problems (Bickerstaff and Walker 2001; Day 2006; Olsen et al. 2001; Stevens et al. 2004; Wakefield et al. 2001).

The authors of several studies concluded that perceived ability to affect social and environmen- 
tal changein one's life affectshow peopleperceive their environment and health (Bickerstaff and Walker 2001; Brown et al. 2004, 2006; Halvorson 2003; H arnish et al . 2006; Potts 2004). In hisstudy of Gulf War illness, Shriver (2001) described senior officials in theVeterans Administration who reportedly controlled compensation claims and medical doctors working for the Veterans Administration as "social control agents." According to Shriver's analysis, they shaped public understanding of environmental illness and its diagnosis and treatment. Three studies identified the ability of lay activists to target and influence "control agents" (i.e., institutional, scientific, and social power structures) as a reason why the medical and scientific communities are now beginning to pay attention to possibleenvironmental contributors to diseases. Potts (2004) compared the breast cancer and environment movementsin the United Statesand in the United Kingdom and observed that in contrast with the United States, in the United Kingdom "women do not feel able to do anything about perceived hazards ... translation of cynicism into action depends on knowledgeand empowerment, which the United Kingdom movement has yet to mobilize." Potts's findings that activists in the United States have become empower ed have been corroborated by another study of the breast cancer and environment movement that specifically identifies power sharing between scientists and lay people as a key component of calling attention to the possible environmental causation of breast cancer (Brown et al. 2006); as oneactivist interviewed said, "Power isn't only knowledge. ... It is bringing new ideas... to the table that scientists may not think about."

\section{Limitations}

For this analysis, several limitations should be noted. The articles discovered by search engines in the literature analysis do not represent the entire realm of qualitative environmental health research, as defined, published in peerreview journals. At least one specific article brought to the author's attention would have met criteriabut was not picked up in thesearch ( $M$ arko et al. 2004). Search engines are limited in their ability to identify and categorize such studies be cause of indexing practices of electronic databases. In particular, the titles and abstracts used to index qualitative studies often do not include summarized research methods (Evans 2002).

It is a limitation that the quality of studies was not evaluated in this analysis and that no attempt was made to examine articles for their mention of methods to reduce bias or to increase the validity of research results, how participants wereidentified and recruited, or theextent to which authors felt the results of their research might be generalized. Although worthy of consideration, these were not objectives of this analysis.

The literature analysis excluded books, book chapters, and "gray literature" (e.g., technical reports, working papers) that may bea substantial contribution to thefield of environmental health.

\section{Discussion and Conclusions}

Qualitative data are published in traditionally quantitative environmental health studies to a limited extent. However, this analysis demonstrates the potential of qualitative data to improve understanding of complex exposure pathways, including the influence of social factors on environmental health, and health outcomes. Qualitative data contribute to the understanding of population exposures by providing data on people's behaviors, perceptions of risk, and the social, economic, cultural, and political considerations that influence personal exposure to environmental health hazards. In several studies these data would not have been captured using quantitative methods. This finding has consequences for the design of epidemiologic studies, particularly when this type of information may modify the relationship between exposure and illness (Lipscomb et al. 2005).

Incorporating qualitative methods into environmental health research may haveimplications for the types of exposures and outcomes typically studied by environmental health scientists. $M$ any qualitative studies identified in this analysis address psychosocial health effects, including social stress, associated with environmental pollution. Some environmental health scientists are beginning to study the effects of physiological responses to stress on mechanisms that contribute to decreased cognitive function, abdominal obesity, hypertension, and other cardiovascular and immune diseases (Krieger 2001; Peterson 1999; Schulz and Northridge 2004). Biomedical approaches often do not incorporatemental and psychological processes. However, if stress is a psychological exposure that is differentially experienced by population subgroups, and the response to stress is physiological, then knowledge gained from qualitative and quantitative inquiry into the physical, sociocultural, and political pro- 
cesses that shapestress responses will further our understanding of the underlying causes and effects of physiologic responses to stress ( $G$ ee and Payne-Sturges 2004).

A large number of studies in this analysis focused on neighborhood effects on health. "Neighborhood" includessocial, physical, biological, and chemical environment: wherewelive; what welive in; and the people, institutions, and social structures we live with. A number of quantitative epidemiological studies haveidentified moderateassociations between neighborhood environment and mortality after adjusting for individual income, employment status, access to medical care, smoking, drinking, exercise, body mass index, and social ties (Kawachi and Berkman 2003). In addition to mortality risk, health outcomes associated with community context includelow birth weight, asthma, injury, and cardiovascular disease (Sampson 2003). Studies identified in this analysiselucidate ways participants related heal th problems to the combined physical, psychological, and social environments in which they live. M acintyre and Ellaway (2003) suggested that many of the individual-level factors epidemiologists tend to control for (e.g., race, income, sex, education) represent variables on the causal pathway between neighborhood exposures and individual health outcomes that demand closer examination. For the qualitative researcher, these variables may represent a goldmine of potentially relevant information for understanding environmental health. Multilevel analyses of neighborhood- and individual-level characteristicsand their contributions to stress suggest that such pathways should be further delineated (Schulz et al. 2008).

Results of this analysis confirm an observation made by Trostle ( 1986 a) more than 20 years ago that most mixed-methods articles combining qualitative and quantitative methods look like the products of either social science or natural science. With few exceptions (Brown et al. 2006; Neudoerffer et al. 2005; Songsore and M cGranahan 1998), the structure of articles more or less conforms to the style and norm appropriate to those intended for professionals in a particular discipline. From the perspective of an environmental health researcher familiar with the quantitative measurements of risk reported in public health journals, the findings of some social sciencearticlesincluded in theliterature analysis were difficult to understand or summarize. The texts each speak to a particular kind of audience, each with a common discourse and shared professional jargon. An anthropologist or social scien- tist with a bias toward the development of theory might be surprised to find so few articles that provide details on analytic methods and theoretical frameworks. The techniques of qualitative research have been used for their practical application, but in few instances are findings related to theory. It is conceivable that theoretical considerations are a stumbling block for collaborations between qualitativeand quantitative investigators, which might explain a relatively large number of publications focused on neighborhood effects on health-a theoretical framework that more than one discipline can hang its hat on. It is also possible that this analysis is a poor measure of actual collaboration between qualitative researchers and environmental health scientists and that intellectual cross-pollination is not well captured in results of such efforts that may be tailored for publication in one or another particular discipline.

No one journal could be identified as the intellectual home of qualitativeenvironmental health research. Among all journals that published any qualitative environmental health research articles at all, the median of such articles per journal was one. It is possible that word limits set by publishers constrain the type of narrative often reported in qualitative studies; for example, theword limit is 8,000 for Social Science and M edicine articles, and 3,500 for the "Research and Practice" articles in the AJPH. The exceptions to the publishing format tend to prove the rule. Second to Health and Place and Social Science and M edicine, each with eight articles, the journal EHP published seven articles. These articles, however, were not typical EHP research articles; they reported on projects supported by the NIEH S community-based participatory research programs and did not conform to the traditional style of research article published in EH P. TheseNIEH S programsstrongly encouraged and in some instances required the participation of lay people, or community residents, in community-based environmental health research. Such research programs, as described and supported by the NIEHS, sometimes included qualitative methods and may have contributed to its legitimatization in environmental health research (O'Fallon and Dearry 2002).

So far, qualitative techniques have not found a fixed home in environmental health scholarly literature. The use of qualitative data in thestudy of environmental health, however, does appear to be increasing over time, along with publications by interdisciplinary teams. Future work might examine opportunities for mixed-meth- 
ods research, including the training of young environmental health investigators in the use of qualitativemethods, and the development of recommendations for journals seeking to publish mixed-methods work such that analytic rigor would meet the standards of both quantitative and qualitative investigators.

\section{References}

Amin S, Basu AM. Popular perceptions of emerging influ-ences on mortality and longevity in Bangladesh and West Bengal. Popul Stud (Camb) 2004; 58(3):357363.

Aragón A, Aragón C, Thörn A. Pests, peasants, and pes-ticides on the northern $\mathrm{Nicaraguan}$ pacific plain. Int J O ccup Environ Health 2001; 7(4):295-302.

Arcury TA, Quandt SA, eds. M igrant and Seasonal Farmworkers and Pesticides: Community-Based Approaches to M easuring Risks and Reducing Exposure. Environ H ealth Perspect 2001; 109(suppl 3):427473.

Arcury TA, Quandt SA, Cravey AJ, Elmore RC, Russell GB. Farmworker reports of pesticide safety and sanitation in the work environment. Am J Ind Med 2001; 39(5):487-498.

Arcury TA, Vallejos QM, M arin AJ, Feldman SR, Smith G, Quandt SA. Latino farmworker perceptions of the risk factors for occupational skin disease. Am J Ind M ed 2006; 49(6):434-442.

Badger D, Nursten J, Williams P, Woodward M. Should all literature reviews be systematic? Eval Res Educ 2000; 14(3, 4):220-230.

Barnes G, Baxter J, Litva A, Staples B. The social and psychological impact of the chemical contamination inci-dent in Weston Village, UK: a qualitative analysis. Soc Sci Med 2002; 55(12):2227-2241.

Bickerstaff K, Walker G. Public understandings of air pollution: the "localisation" of environmental risk. Global Environ Change 2001; 11:133-145.

Bolam B, M urphy S, Gleeson K. Place-identity and geographical inequalities in health: a qualitative study. Psychol Health 2006; 21(3):399-420.

Bowie J, Farfel M, Moran $\mathrm{H}$. Community experiences and perceptions related to demolition and gut rehabilita-tion of houses for urban redevelopment. J U rban Health 2005; 82(4):532-542.

Brown P. Qualitative methods in environmental health research. Environ Health Perspect 2003; 111:17891798.

Brown P, Mayer B, Zavestoski S, Luebke T, M andelbaum J, M cCormick $S$. Clearing the air and breathing freely: the health politics of air pollution and asthma. Int J Health Serv 2004; 34(1):39-63.

Brown P, McCormick S, Mayer B, Zavestoski S, Morello-Frosch R, Senier L. "A lab of our own"-environmental causation of breast cancer and challenges to the dominant epidemiological paradigm. Sci Technol Human Values 2006; 31(5):499-536.
Bush J, Moffatt S, Dunn C. "Even the birds round here cough": stigma, air pollution and health in Teesside. Health Place 2001; 7(1):47-56.

Butchart A, Kruger J, Lekoba R. Perceptions of injury causes and solutions in a Johannesburg township: impli-cations for prevention. Soc Sci M ed 2000; 50(3):331-344.

Cooper S, Darragh A, Vernon S, Stallones L, M acNaughton N, Robison T, Hanis C, Zahm SH. Ascertainment of pesticide expo-sures of migrant and seasonal farmworker children: find-ings from focus groups. Am J Ind M ed 2001; 40(5):531-537.

Day RJ. Traffic-related air pollution and perceived health risk: lay assessment of an everyday hazard. H ealth Risk Soc 2006; 8(3):305-322.

Day R. Local environments and older people's health: dimensions from a comparative qualitative study in Scotland. Health Place 2008; 14(2):299-312.

Doria M F, Abubakar I, Syed Q, Hughes S, Hunter PR. Perceived causes of sporadic cryptosporidiosis and their relation to sources of information. J Epidemiol Community Health 2006; 60(9):745-750.

Dunn FL, Janes CR. Introduction: medical anthropology and epidemiology. In: Gifford SM, Janes CR, Stall R, editors. Anthropology and Epidemiology. Dordrecht, Holland: D. Reidel; 1986. p. 3-34

Elliott SJ. A comparative analysis of public concern over solid waste incinerators. Waste M anage Res 1998; 16(4):351-364.

Elliott SJ, Cole DC, Krueger P, Voorberg N, Wakefield S. The power of perception: health risk attributed to air pol-lution in an urban industrial neighbourhood. Risk Anal 1999; 19(4):621-634.

Engvall K, Norrby C, Sandstedt E. The Stockholm Indoor Environment Questionnaire: a sociologically based tool for the assessment of indoor environment and health in dwell-ings. Indoor Air 2004; 14(1):24-33.

Espino $F, M$ anderson L, Acuin C, Domingo F, Ventura E. Perceptions of malaria in a low endemic area in the Philippines: transmission and prevention of disease. Acta Trop 1997; 63(4):221-239.

Evans D. Database searches for qualitative research. J Med Libr Assoc 2002; 90(3):290-293.

Eyles J, Taylor SM, Johnson N, Baxter J. Worrying about waste: living close to solid waste disposal facilities in southern Ontario. Soc Sci M ed 1993; 37(6):805812. 
Finlay L. "Outing" the researcher: the provenance, process, and practice of reflexivity. Qual Health Res 2002; 12(4):531-545.

Flocks J, Clarke L, Albrecht S, Bryant C, M onaghan P, Baker $\mathrm{H}$. Implementing a community-based social market-ing project to improve agricultural worker health. Environ Health Perspect 2001; 109(Suppl. 3): $461-468$.

Foster M W, Sharp RR. Will investments in large-scale prospective cohorts and biobanks limit our ability to dis-cover weaker, less common genetic and environmen-tal contributors to complex diseases? Environ Health Perspect 2005; 113:119-122.

Furgal C, Seguin J. Climate change, health, and vul-nerability in Canadian northern aboriginal communities. Environ Health Perspect 2006; 114:19641970.

Gee GC, Payne-Sturges DC. Environmental health dispari-ties: a framework integrating psychosocial and environ-mental concepts. Environ Health Perspect 2004; 112:1645-1653.

Green J, Hart L. Children's views of accident risks and prevention: a qualitative study. Inj Prev 1998; $4(1): 14-21$.

Green L, Fullilove M, Evans D, Shepard P. "Hey, mom, thanks!": use of focus groups in the development of place-specific materials for a community environmental action campaign. Environ $\mathrm{H}$ ealth Perspect 2002; 110(Suppl. 2):265-269.

Haines M M, Brentnall SL, Stansfeld SA, Klineberg E. Qualitative responses of children to environmental noise. N oise Health 2003; 5(19):19-30

Halvorson SJ. A geography of children's vulnerability: gender, household resources, and water-related disease hazard in northern Pakistan. Prof Geogr 2003; 55(2):120-133.

Halvorson SJ. Women's management of the household health environment: responding to childhood diarrhea in the northern areas, Pakistan. H ealth Place 2004; 10(1):43-58.

Hammal F, Mock J, Ward KD, Fouad M F, Beech BM, $M$ aziak W. Settling with danger: conditions and health problems in peri-urban neighbourhoods in Aleppo, Syria. Environ U rban 2005; 17(2):113-125. [accessed 2010 Jun 30]. Available: http:// eau. sagepub.com/content/17/2/113.

Harnish KE, Butterfield P, Hill WG. Does Dixon's integrative environmental health model inform an under-standing of rural parents' perceptions of local environ-mental health risks? Public $\mathrm{H}$ ealth Nurs 2006; 23(5):465-471.

Harper J. Breathless in Houston: a political ecology of health approach to understanding environmental health concerns. M ed Anthropol 2004; 23(4):295326.

Héon-Klin V, Sieber E, Huebner J, Fullilove MT. The influ-ence of geopolitical change on the well-being of a popula-tion: the Berlin wall. Am J Public H ealth 2001; 91(3):369-374.

Higgins JPT, Green S, editors. Cochrane Handbook for Systematic Reviews of Interventions 4.2.6 [updated 2006 Sep]. Chichester, UK: John Wiley \& Sons, Ltd.; 2006.

Imai N, Imai $\mathrm{Y}$, Kido $\mathrm{Y}$. Psychosocial factors that aggra-vate the symptoms of sick house syndrome in Japan. Nurs Health Sci 2008; 10(2):101-109.
Israel BA, Schulz AJ, Estrada-M artinez L, Zenk SN, Viruell-Fuentes E, Villarruel AM, Stokes C. Engaging urban resi-dents in assessing neighborhood environments and their implications for health. J U rban $\mathrm{H}$ ealth 2006; 83(3):523-539.

James J, Eyles J. Perceiving and representing both health and the environment: an exploratory investigation. Qual Health Res 1999; 9(1):86-104.

Järvelä M, Rinne-Koistinen EM. Purity and dirt as social constructions: environmental health in an urban shanty-town of Lagos. Int J U rban Reg Res 2005; 29(2):375-388.

Kamphuis CB, van Lenthe FJ, Giskes K, Brug J, Mackenbach JP. Perceived environmental determinants of physi-cal activity and fruit and vegetable consumption among high and low socioeconomic groups in the $\mathrm{N}$ etherlands. Health Place 2007; 13(2):493-503.

Kawachi I, Berkman LF. Introduction. In: Kawachi I, Berkman LF, editors. Neighborhoods and $\mathrm{H}$ ealth. New York: Oxford University Press; 2003. p. 1-19

Krenichyn $\mathrm{K}$. "The only place to go and be in the city": women talk about exercise, being outdoors, and the mean-ings of a large urban park. Health Place 2006; 12(4):631-643.

Krieger $\mathrm{N}$. Theories for social epidemiology in the 21st cen-tury: an ecosocial perspective. Int J Epidemiol 2001; 30(4):668-677.

Lambert TW, Guyn L, Lane SE. Development of local knowl-edge of environmental contamination in Sydney, Nova Scotia: environmental health practice from an environmen-tal justice perspective. Sci Total Environ 2006; 368(2-3):471-484.

Larsson LS, Butterfield P, Christopher S, Hill W. Rural com-munity leaders' perceptions of environmental health risks: improving community health. $\mathrm{AAOHN}$ | 2006; 54(3):105-112.

Lipscomb HJ, Argue R, M CD onald MA, Dement JM, Epling CA, James T, Wing S, Loomis D. Exploration of work and health dispar-ities among black women employed in poultry processing in the rural South. Environ H ealth Perspect 2005; 113:1833-1840.

Lobdell DT, Gilboa S, Mendola P, Hesse BW. Use of focus groups for the environmental health researcher. J Environ Health 2005; 67(9):36-42.

M acintyre S, Ellaway A. N eighborhoods and health: an overview. In: Kawachi I, Berkman LF, editors. Neighborhoods and Health. New York: Oxford University Press; 2003. p. 20-44

MacQueen KM, McLellan E, Kay K, M ilstein B. Codebook development for team-based qualitative analysis. Cult Anthropol M ethods 1998; 10(2):31-36.

M alterud K. Qualitative research: standards, challenges, and guidelines. Lancet 2001; 358(9280):483-488.

Marko J, Soskolne CL, Church J, Francescutti LH, Anielski M. Development and application of a framework for analysing the impacts of urban transportation. EcoH ealth 2004; 1(4):374-386.

M cCauley L, Beltran M, Phillips J, Lasarev M, Sticker $D$. The Oregon migrant farmworker community: an evolving model for participatory research. Environ Health Perspect 2001; 109(Suppl. 3):449-455.

M essias DK, Lacy E. Katrina-related health concerns of Latino survivors and evacuees. I Health Care Poor Underserved 2007: 18(2):443-464. 
Michael YL, Green M K, Farquhar SA. N eighborhood design and active aging. $\mathrm{H}$ ealth Place 2006; 12(4):734740.

M offatt S, Phillimore P, Bhopal R, Foy C. "If this is what it's doing to our washing, what is it doing to our lungs?" Industrial pollution and public understanding in northeast England. Soc Sci Med 1995; 41(6):883-891.

Moffatt S, Pless-Mulloli T. "It wasn't the plague we expected." Parents' perceptions of the health and envi-ronmental impact of opencast coal mining. Soc Sci M ed 2003; 57(3):437-451.

Neudoerffer RC, Waltner-Toews D, Kay JJ, Joshi DD, Tamang MS. A diagrammatic approach to understanding complex eco-social interactions in Kathmandu, N epal. EcolSociety 2005; 10(2):12. [accessed 2010 Jun 30]. Available: http:// www.ecologyandsociety.org/vol10/iss2/art12/

Noyes J, Popay J. Directly observed therapy and tubercu-losis: how can a systematic review of qualitative research contribute to improving services? A qualitative meta-synthesis. J Adv Nurs 2007; 57(3):227-243.

O'Fallon LR, Dearry A. Community-based participatory research as a tool to advance environmental health sci-ences. Environ $\mathrm{H}$ ealth Perspect 2002; 110(Suppl. 2):155-159.

Olsen A, Samuelsen H, Onyango-Ouma W. A study of risk factors for intestinal helminth infections using epide-miological and anthropological approaches. J Biosoc Sci 2001; 33(4):569-584.

Patton M Q. Qualitative Research and Evaluation M ethods. Thousand Oaks, CA: Sage; 2002.

Peres F, Moreira JC, Rodrigues KM, Claudio L. Risk per-ception and communication regarding pesticide use in rural work: a case study in Rio de Janeiro State, Brazil. Int J Occup Environ Health 2006; 12(4):400-407.

Peterson CL. Stress at Work: A Sociological Perspective. New York: Baywood; 1999.

Petitti DB. M eta-Analysis, Decision Analysis, and CostEffectiveness Analysis. New York: Oxford University Press; 2000.

Phaswana-M afuya N, Shukla N. Factors that could moti-vate people to adopt safe hygienic practices in the Eastern Cape Province, South Africa. Afr $H$ ealth Sci 2005; 5(1):21-28.

Popay J, Bennett S, Thomas C, Williams G, Gatrell A, Bostock L. Beyond "beer, fags, egg and chips"? Exploring lay understandings of social inequalities in health. Sociol Health III 2003; 25(1):1-23.
Potts L. M apping citizen expertise about environmental risk of breast cancer. Crit Soc Pol 2004; 24(4):550574.

Rao P, Arcury TA, Quandt SA, Doran A. North Carolina growers' and extension agents' perceptions of Latino farmworker pesticide exposure. Hum Organ 2004; 63(2):151-161.

Regan G, Lee RE, Booth K, Reese-Smith J. Obesogenic influences in public housing: a mixed-method analysis. Am J Health Promot 2006; 20(4):282-290.

Rice C, Birnbaum LS, Cogliano J, M ahaffey K, N eedham L, Rogan WJ, vom Saal FS. Exposure assessment for endocrine disruptors: some considerations in the design of studies. Environ Health Perspect 2003; 111:1683-1690

Richards R, Smith C. Environmental, parental, and personal influences on food choice, access, and overweight status among homeless children. Soc Sci M ed 2007; 65(8):1572-1583.

Ries AV, Voorhees CC, Gittelsohn J, Roche KM, Astone NM. Adolescents' perceptions of environmental influ-ences on physical activity. Am J Health Behav 2008; 32(1):26-39.

Rosenfield P. The potential of transdisciplinary research for sustaining and extending linkages between the health and social sciences. Soc Sci Med 1992; 35(11):1343-1357.

Salazar MK, Napolitano M, Scherer JA, M cCauley LA. $\mathrm{H}$ ispanic adolescent farmworkers' perceptions associated with pesticide exposure. West J Nurs Res 2004; 26(2):146-166.

Sampson RJ. The neighborhood context of well-being. Perspect Biol M ed 2003; 46(3 Suppl.):S53-S64.

Sandelowski M, Docherty S, Emden C. Focus on qualita-tive methods. Qualitative metasynthesis: issues and tech-niques. Res Nurs Health 1997; 20(4):365-371.

Schaefer-MCDaniel N. "They be doing illegal things": early adolescents talk about their inner-city neighbor-hoods. J Adolesc Res 2007; 22(4):413-436.

Schulz A, N orthridge ME. Social determinants of health: implications for environmental health promotion. Health Educ Behav 2004; 31(4):455-471.

Schulz AJ, Zenk SN, Israel BA, Mentz G, Stokes C, Galea S. Do neighborhood economic characteristics, racial composition, and residential stability predict perceptions of stress associated with the physical and social environ-ment? Findings from a multilevel analysis in Detroit. J U rban $\mathrm{H}$ ealth 2008; 85(5):642-661. 
Shriver TE. Environmental hazards and veterans' framing of Gulf War illness. Sociol Inq 2001; 71(4):403420.

Shriver TE, White DA, Kebede A. Power, politics, and the framing of environmental illness. Sociol Inq 1998; 68(4):468-475.

Snape $D$, Spencer $L$. The foundations of qualitative research. In: Ritchie J, Lewis J, editors. Qualitative Research Practice: A Guide for Social Science Students and Researchers. Thousand Oaks, CA: Sage; 2003. p. $1-23$.

Songsore J, M cGranahan G. The political economy of household environmental management: gender, environ-ment and epidemiology in the Greater Accra metropolitan area. World D ev 1998; 26(3):395412.

Stemler S. An overview of content analysis. Pract Assess, Res Eval [serial on the Internet] 2001 [accessed 2010 Jul 5] 7(17). Available: http://pareonline.net/ getvn. asp?v=7\&n=17.

Stevens E, Cullinan P, Colvile R. Urban air pollution and children's asthma: what do parents and health profession-als think? Pediatr Pulmonol 2004; 37(6):530-536.

Stokols D. Toward a science of transdisciplinary action research. Am J Community Psychol 2006; 38(1-2):6377.

Taylor SM, Elliott S, Eyles J, Frank J, Haight M, Streiner D, Walter S, White N, Willms D. Psychosocial impacts in populations exposed to solid-waste facilities. Soc Sci M ed 1991; 33(4):441-447.

Thompson B, Coronado G, Puschel K, Allen E. Identifying constituents to participate in a project to control pesti-cide exposure in children of farmworkers. Environ H ealth Perspect 2001; 109(Suppl. 3):443448.

Thompson B, Coronado G, Vigoren EM, Griffith WC, Fenske RA, Kissel JC, Shirai JH, Faustman EM. Para niños saludables: a community intervention trial to reduce organophosphate pesticide expo-sure in children of farmworkers. Environ $\mathrm{H}$ ealth Perspect 2008; 116:687-694.

Timmermans $\mathrm{S}$. Why modest geographic effects for asthma? Pharmaceutical treatment as neutralizing mecha-nism. Health (London) 2007; 11(4):431-454.

Trayers T, Deem R, Fox KR, Riddoch CJ, Ness AR, Lawlor DA. Improving health through neighbourhood environ-mental change: are we speaking the same language? A qualitative study of views of different stakeholders. J Public Health 2006; 28(1):4955.
Trostle J. Early work in anthropology and epidemiology: from social medicine to the germ theory, 1840 to 1920. In: Gifford SM, Janes CR, Stall R, editors. Anthropology and Epidemiology. Dordrecht, Holland: D. Reidel; 1986a. p. 35-58.

Trostle J. Anthropology and epidemiology in the twen-tieth century: a selective history of collaborative projects and theoretical affinities, 1920-1970. In: Gifford SM, Janes CR, Stall R, editors. Anthropology and Epidemiology. Dordrecht, Holland: D. Reidel; 1986b. p. 59-96.

Tu K, Donham K, Ziegenhorn R, Reynolds S, Thorne PS, Subramanian P, Whitten P, Stookesberry J. A control study of the physical and mental health of residents living near a large-scale swine operation. J Agric Saf Health 1997; 3(I):13-26.

Ulin PR, Robinson ET, Tolley EE. Q ualitative M ethods in Public Health. San Francisco: Jossey-Bass; 2005.

Vandermoere $\mathrm{F}$. The process of soil excavation in a community- site-specific determinants of stress percep-tion. Environ Behav 2006; 38(5):715-739.

Wakefield SE, Elliott SJ, Cole DC, Eyles JD. Environmental risk and (re)action: air quality, health, and civic involve-ment in an urban industrial neighbourhood. Health Place 2001; 7(3):163-177.

Warr DJ, Tacticos T, Kelaher M, Klein H. "M oney, stress, jobs": residents' perceptions of health-impairing factors in "poor" neighbourhoods. H ealth Place 2007; 13(3):743-756.

Wernham A. Inupiat health and proposed Alaskan oil development: results of the first integrated health impact assessment/environmental impact statement for pro-posed oil development on Alaska's north slope. EcoH ealth 2007; 4(4):500-513.

Wing S. Limits of epidemiology. Med Global Survival 1994; 1(2):74-86.

Wing $\mathrm{S}$. Objectivity and ethics in environmental health science. Environ Health Perspect 2003; 111:18091818.

Wing S, Horton RA, Muhammad N, Grant GR, Tajik M, Thu K. Integrating epidemiology, education, and organizing for environmental justice: community health effects of indus-trial hog operations. Am J Public H ealth 2008; 98(8):1390-1397.

Yen IH, Scherzer T, Cubbin C, Gonzalez A, Winkleby MA. Women's perceptions of neighborhood resources and haz-ards related to diet, physical activity, and smoking: focus group results from economically distinct neighborhoods in a mid-sized U.S. City. Am J Health Promot 2007; 22(2):98-106. 